\title{
Study of TEC, slab-thickness and neutral temperature of the thermosphere in the Indian low latitude sector
}

\author{
K. Venkatesh, P. V. S. Rama Rao, D. S. V. V. D. Prasad, K. Niranjan, and P. L. Saranya \\ Space Physics Laboratory, Department of Physics, Andhra University, Visakhapatnam, India \\ Received: 17 March 2011 - Revised: 9 August 2011 - Accepted: 19 September 2011 - Published: 26 September 2011
}

\begin{abstract}
The ionospheric equivalent slab-thickness is an important parameter which measures the skewness of the electron density profile of the ionosphere. In this paper, the diurnal, seasonal, day-to-day and latitudinal variations of ionospheric parameters namely total electron content (TEC), the peak ionization density of F-layer $(N m \mathrm{~F} 2)$, equivalent slab-thickness $(\tau)$ and neutral temperature $\left(T_{\mathrm{n}}\right)$ are presented. The simultaneous data of GPS-TEC and $N m \mathrm{~F} 2$ from Trivandrum $\left(8.47^{\circ} \mathrm{N}, 76.91^{\circ} \mathrm{E}\right)$, Waltair $\left(17.7^{\circ} \mathrm{N}, 83.3^{\circ} \mathrm{E}\right)$ and Delhi $\left(28.58^{\circ} \mathrm{N}, 77.21^{\circ} \mathrm{E}\right)$ are used to compute the slabthickness $(\tau=\mathrm{TEC} / N m \mathrm{~F} 2)$ of the low sunspot period, 20042005. The day-time TEC values at Waltair are found to be greater than those at Trivandrum, while at Delhi the day-time TEC values are much lower compared to those at Trivandrum and Waltair. The trends of variation in the monthly mean diurnal variation of TEC and $N m \mathrm{~F} 2$ are similar at Delhi, while they are different at Trivandrum and Waltair during the daytime. The slab-thickness $(\tau)$ has shown a pre-sunrise peak around 05:00 LT at all the three stations, except during the summer months over Delhi. A consistent secondary peak in slab-thickness around noon hours has also been observed at Trivandrum and Waltair. During equinox and winter months a large night-time enhancement in the slab-thickness (comparable to the early morning peak in slab-thickness) is observed at Delhi. The latitudinal variation of slab-thickness has shown a decrease from the equatorial station, Trivandrum to the low-mid latitude station, Delhi. The neutral temperatures $\left(T_{\mathrm{n}}\right)$ computed from the slab-thickness $(\tau)$ has shown a sharp increase around 05:00 LT over Trivandrum and Waltair. Whereas at Delhi, a double peaking around 05:00 and 23:00 LT is observed during winter and equinoctial months. The neutral temperatures computed are compare well with those of the MSIS-90 model derived temperatures.
\end{abstract}

Keywords. Ionosphere (Equatorial ionosphere; Ionospheric disturbances; Plasma temperature and density)

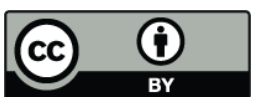

Correspondence to: P. V. S. Rama Rao (palurivsrao@gmail.com)

\section{Introduction}

It is known that the equatorial and low latitude ionospheres are more dynamic and play a critical role in the transionospheric communication and navigation systems. Total Electron Content (TEC) measurements using the radio beacons on the low orbiting and geostationary satellites have extensively been used to study the morphological features of the different ionospheric parameters. During the past few decades, several researchers have made significant contributions by making individual measurements of TEC from various locations in India (Rastogi et al., 1975; Aravindan and Iyer, 1990; Bhuyan and Borah, 2007; Bagiya et al., 2009). In the recent years, with the increasing demand on the transionospheric communication systems used in the navigation of space borne vehicles, such as satellites, aircrafts, as well as surface transportation systems, the measurement of the true value of the total electron content of the ionosphere has become important for making appropriate range corrections, as well as in accounting for errors introduced in the range delays owing to the effects of space weather related events, such as geomagnetic storms and signal scintillations due to ionospheric irregularities. In the recent past the GPS technique of measuring total electron content of the ionosphere has become an effective tool for continuous and simultaneous measurement of TEC from different geographic locations. The measurement of the total electron content and peak electron density of the F2-layer $(\mathrm{NmF} 2)$ in the Indian sector has gained special importance in the recent years.

The ionospheric slab-thickness $(\tau)$ which is the ratio of TEC and F2-layer peak electron density $(\mathrm{NmF} 2)$ $(\tau=\mathrm{TEC} / N m \mathrm{~F} 2)$ provides a measure of the skewness of the vertical distribution of the ionization. It represents the equivalent thickness of the ionosphere having a constant uniform density equal to that of the F2-layer peak. It is capable of addressing many ionospheric phenomena and has been studied over the last few decades (Bhuyan et al., 1986; Davies and Liu, 1991; Gulyaeva et al., 2004). The variations of TEC (Ooty), NmF2 (Kodaikanal) and the slab-thickness were

Published by Copernicus Publications on behalf of the European Geosciences Union. 
investigated by Rastogi et al. (1979) and Sethia et al. (1980) for the low solar activity period 1975-1976 using ATS phaseII measurements over the Indian equatorial region. Slabthickness contains all the new information obtainable form TEC measurements which is not readily available in $f o \mathrm{~F} 2$ (Titheridge, 1973). The diurnal, day-to-day, seasonal and geomagnetic variations of ionospheric slab-thickness in the Indian low and mid latitude regions have been investigated by many researchers (Rastogi et al., 1977; Bhuyan et al., 1986). Since both TEC and $N m \mathrm{~F} 2$ exhibit a marked latitudinal variation over the equatorial region, it is of interest to examine the latitudinal variation of their ratio, i.e. the slab-thickness $(\tau)$ parameter over the equatorial and low latitude regions.

Slab-thickness is a significant parameter since it contains the information regarding the neutral temperature and, for an assumed electron density profile, it can be related directly to the scale height of the ionizable constituents. Slab-thickness has been used by a number of workers as an index of temperature (Bhonsle et al., 1965; Hibberd and Ross, 1966). Yeh and Flaherty (1966) have derived an empirical relation between the electron to ion temperature ratio $\left(T_{\mathrm{e}} / T_{\mathrm{i}}\right)$ and slabthickness for a hybrid model with Chapman type on bottom side and diffusion type transport on topside. The slabthickness depends on the scale height of the ionizable constituents and the scale height of loss processes, both of which are dependent on neutral temperature and hence can be indicated by the slab-thickness (Mahajan et al., 1968; Titheridge, 1973; Pande et al., 1984).

Studies on the ionospheric parameters (TEC, $N m \mathrm{~F} 2, \tau, T_{\mathrm{n}}$ ) are of vital importance over equatorial and low latitude region, where the electromagnetic drift plays a significant role in the distribution of ionization in the F-region. This paper reports the TEC, $N m \mathrm{~F} 2$ and slab-thickness variations over Trivandrum, Waltair and Delhi respectively in the Indian sector. The morphological (diurnal, day-to-day, seasonal and latitudinal) features have been studied and reported in this paper. Further, the neutral temperatures from these three stations have also been presented and are compared with the MSIS-90 model derived temperatures.

\section{Data and method of analysis}

The total electron content (TEC) data derived from the dual frequency $\left(\mathrm{L}_{1}=1575.42 \mathrm{MHz}\right.$ and $\left.\mathrm{L}_{2}=1227.60 \mathrm{MHz}\right) \mathrm{GPS}$ receivers (model: Novatel 4004b) from three different Indian stations namely Trivandrum $\left(8.47^{\circ} \mathrm{Geog}\right.$. North, $76.91^{\circ}$ Geog. East, $0.63^{\circ}$ Geomag. South, $0.6^{\circ} \mathrm{S}$ dip lat.), an equatorial station, Waltair $\left(17.7^{\circ} \mathrm{Geog}\right.$. North, $83.3^{\circ} \mathrm{Geog}$. East, $6.4^{\circ}$ Geomag. North, $20.0^{\circ} \mathrm{N}$ dip lat.), a station located at the inner-edge of the Equatorial Ionization Anomaly (EIA) and Delhi $\left(28.58^{\circ}\right.$ Geog. North, $77.21^{\circ}$ Geog. East, $19.2^{\circ}$ Geomag. North, $42.4^{\circ} \mathrm{N}$ dip lat.), a station located at the outer edge of the EIA for the low sunspot period from March 2004 to February 2005 (mean $\mathrm{Rz}=39$ ) are considered for the present study. These three GPS receivers are among the constellation of 18 receivers installed by Airport Authority of India (AAI) and Indian Space Research Organization (ISRO) under Indian GAGAN programme for aircraft landing and navigation purposes. Data from all the receivers is collected and corrections for satellite and receiver biases for each individual receiver have been carried out at Space Applications Centre (SAC), ISRO, Ahmedabad and the calibrated data is provided for users.

Simultaneous $N m \mathrm{~F} 2$ data obtained from three identical ionosondes (KEL, IPS-42) located at the above three stations is considered for the present study. These ionosondes are operated in the frequency range 1 to $22 \mathrm{MHz}$ with $5 \mathrm{KW}$ transmitting power and $41.67 \mu$ s pulse width. They sound the ionosphere at regular intervals by the pulse-echo technique at vertical incidence and plot the relationship between the virtual height to the frequency of reflection and the ionogram is stored by recording on a magnetic tape. Simultaneous TEC and $\mathrm{NmF} 2$ data is used for computing the equivalent slabthickness $(\tau)$ using the relation

$\tau=\mathrm{TEC} / N m \mathrm{~F} 2(\mathrm{~km})$

The slab-thickness values thus derived are used to compute the neutral temperature $\left(T_{\mathrm{n}}\right)$ of the thermosphere using the method proposed by Titheridge (1973). The MSIS90 model derived temperatures have also been obtained from the website (http://omniweb.gsfc.nasa.gov/vitmo/msis vitmo.html) and a comparison between the two has been made.

\section{Results and discussion}

\subsection{Variation of Total Electron Content (TEC)}

The monthly mean diurnal variation plots of TEC over the three different stations Trivandrum (Blue curve), Waltair (Green curve) and Delhi (Red curve) for each month are presented in Fig. 1. It is readily seen from this figure that the diurnal variation of TEC over Trivandrum typically shows a sharp day minimum of about 5 TECU around 06:00 LT and a broad day maximum with TEC varying from 30 to $50 \mathrm{TECU}$ in all the three different seasons. Night-time maintenance of ionization is observed over Trivandrum particularly during winter and equinoctial months with TEC values varying from 5 to $20 \mathrm{TECU}$, whereas during the summer months, the night-time ionization varies from 5 to 10 TECU.

It is observed that the day maximum values of TEC at Waltair are higher than those at Trivandurm. Similar to that at Trivandrum, a sharp day minimum is observed around 06:00 LT followed by a broad day maximum. The nighttime maintenance of ionization has also been observed during equinoctial months whereas, during summer and winter months, the night-time ionization is reduced and varies between 5 and 10 TECU. The day maximum TEC values 

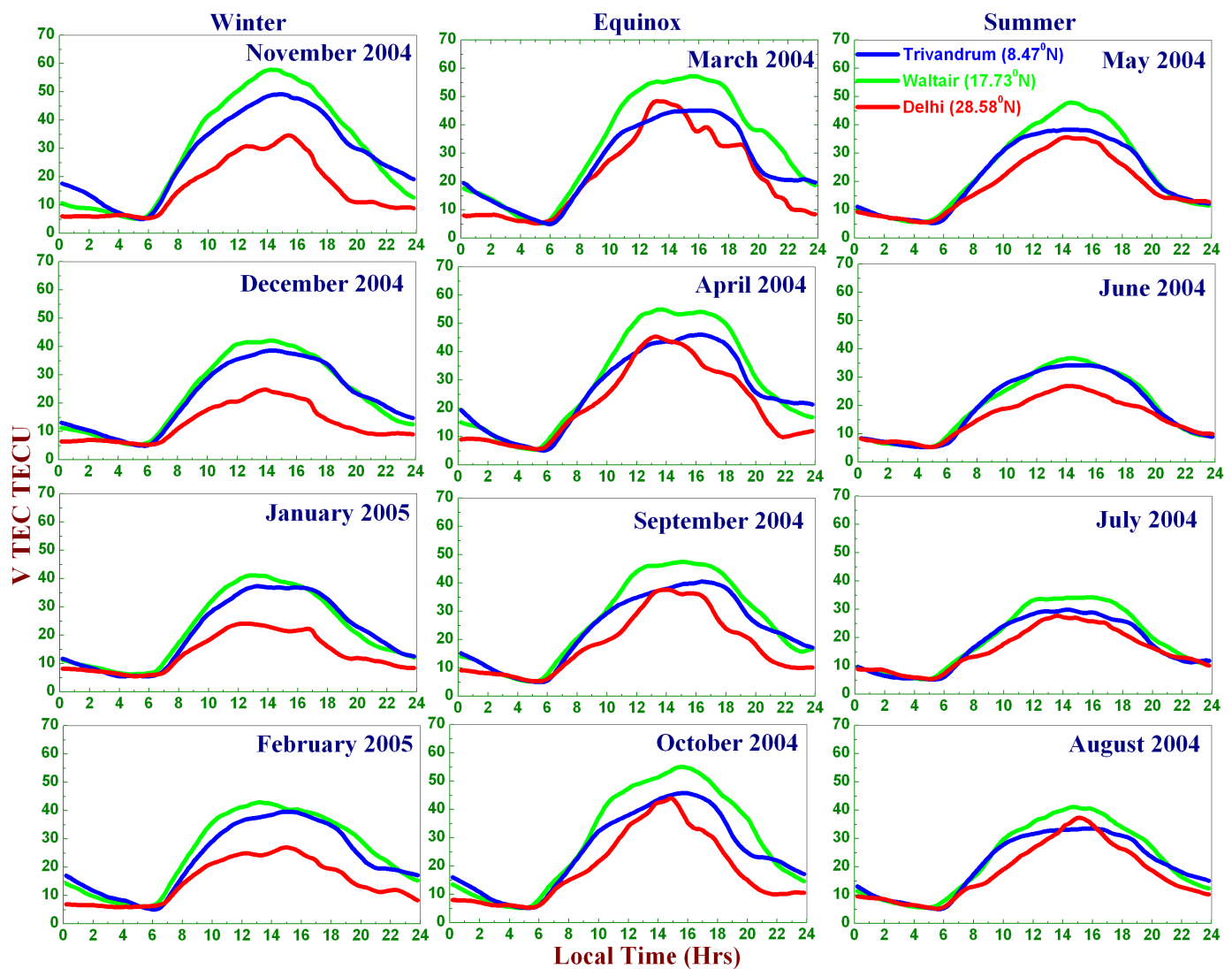

Fig. 1. Comparison of monthly mean diurnal variation of TEC over three different stations Trivandrum $\left(8.47^{\circ} \mathrm{N}, 76.91^{\circ} \mathrm{E}\right)$, Waltair $\left(17.7^{\circ} \mathrm{N}\right.$, $\left.83.3^{\circ} \mathrm{E}\right)$ and Delhi $\left(28.58^{\circ} \mathrm{N}, 77.21^{\circ} \mathrm{E}\right)$ during three different seasons.

during equinoctial months are higher (around 60 TECU) compared to those in summer and winter months (around 30 to 40 TECU). Bagiya et al. (2009) have also reported that the TEC values during equinoctial months are higher compared to those during the other seasons using the GPS TEC derived over Rajkot in the Indian region. It is also seen from this figure that the TEC values over Delhi are in general much lower than those at the other two latitudes during all hours of the day. The sharp day minimum observed at Trivandrum and Waltair is absent at Delhi. The TEC values during summer and winter months are lower compared to those of equinoctial months. The night-time TEC values at Delhi are low and mostly flat at the day minimum level during all the three seasons.

Understanding the day-to-day variability of TEC is of scientific interest in view of the causative mechanisms and is of great importance in assessing prediction capabilities. Rastogi and Alex (1987), and Aravindan and Iyer (1990) investigated the variability of TEC in the Indian low latitude sector using data obtained from Faraday Rotation measurements. Dabas et al. (1984) observed that day-to-day changes in TEC in the Indian zone occur in the form of single day abnormality, alternate day abnormality, and long-term periodic fluctuations of 27 and 45 days, all of which are apparently controlled by the equatorial electroject and not always correlated with solar and magnetic changes. To study the dayto-day variability in TEC, the mean diurnal variation plots of TEC along with their standard deviation represented by error bars during three typical months (December, September and May 2004) representing three different seasons (winter, equinox and summer respectively) over the three different stations namely Trivandrum, Waltair and Delhi have been plotted and are presented in Fig. 2. A significant day-to-day variability is observed over the three different stations during all the three different seasons. The day-to-day variability in the day maximum values of TEC over the equatorial station, Trivandrum is significantly low compared to that at the other two stations, Waltair and Delhi, located on either sides of the crest of the equatorial ionization anomaly. The day-to-day variability during the equinoctial months is higher compared to that of winter and summer months over the three different stations. Bhuyan and Borah (2007) have also reported that the day to day variability is less at the equator as compared to that at the crest regions of the anomaly. Rastogi and Alex (1987) and Aravind and Iyer (1990) showed that, during low solar activity and during day-time, the variability in TEC is 


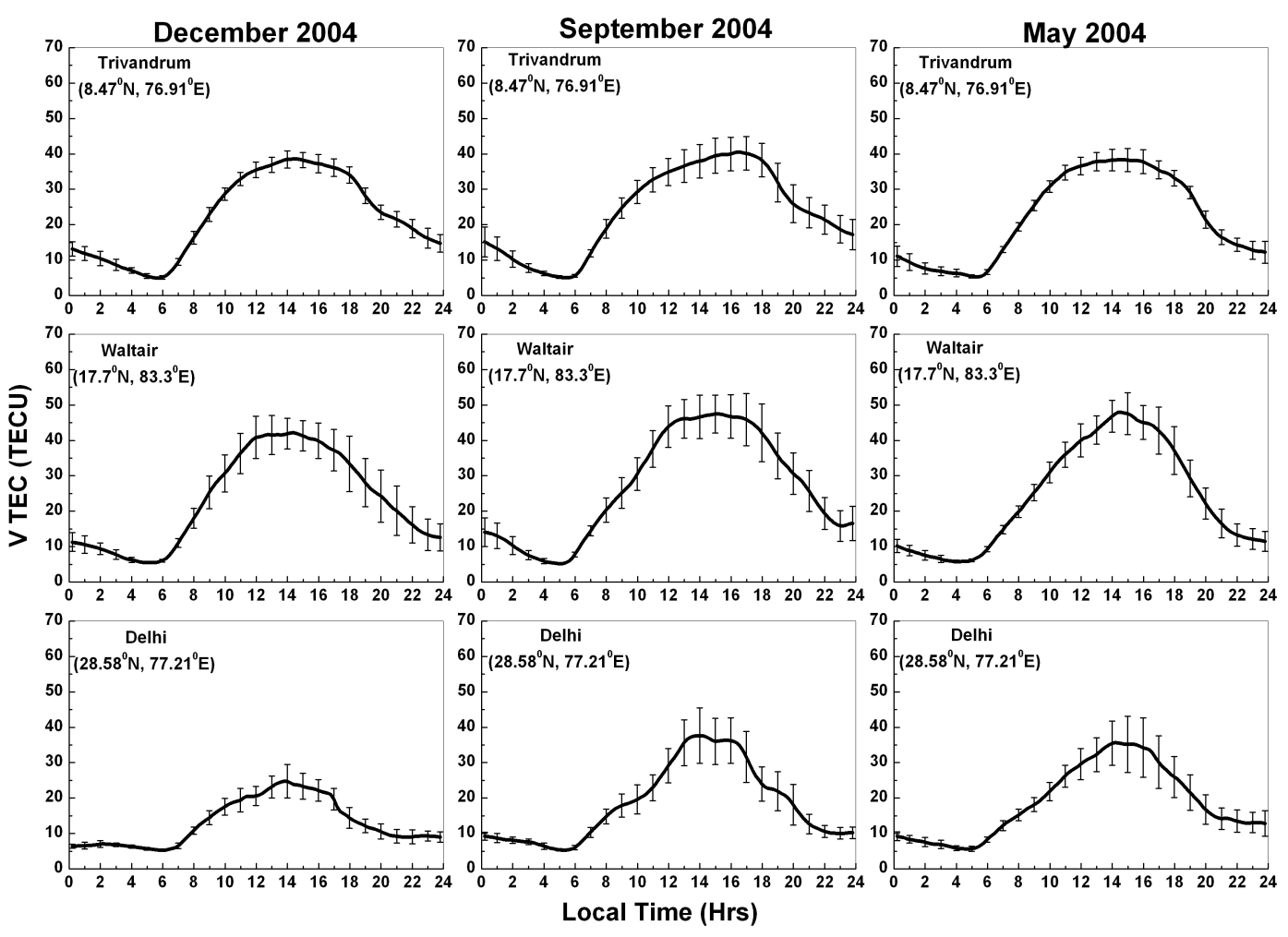

Fig. 2. Mean diurnal variation of TEC along with standard deviation as error bars during three typical months (December, September and May 2004) representing three different seasons (winter, equinox and summer) for the three different stations namely Trivandrum, Waltair and Delhi.

lowest at the magnetic equator and progressively increases towards the crest region. This day-to-day variation in TEC may be attributed to the changes in the activity of the sun itself and to the associated changes in the intensity of the incoming solar radiations in addition to the changes which take place in the earth's magnetic field and the equatorial electrojet (EEJ) strength, added to the effects of the contribution from the neutral winds (Rama Rao et al., 1977).

An interesting feature in India is that the magnetic equator passes through the southernmost tip of the country and the Indian region extends upto the low mid latitudes $\left(38^{\circ}\right.$ Geographic Latitude North) which gives an unique opportunity to study the latitudinal variation of the ionospheric TEC which is mostly dictated by the phenomenon of equatorial ionization anomaly (EIA). It may be seen from Fig. 1 that there is a significant latitudinal variation in the day maximum values of TEC with minimum values at Delhi and maximum values over Waltair. The day-time TEC values over Waltair are higher during equinoctial months compared to those at Trivandrum and Delhi. The night-time ionization during winter and equinoctial months is higher over Waltair and Trivandrum compared to those at Delhi. However, the TEC values at Delhi are lower than those at the other two stations in all the three different seasons showing the typical features of a mid-latitude station. These latitudinal changes in TEC are due to the $\boldsymbol{E} \times \boldsymbol{B}$ drifts occurring at the equator causing the diffusion of plasma which deposits more ionization at the anomaly crest region causing a decrease in the ionization at the equatorial latitudes.

\subsection{Variation of peak electron density of the F2-layer (NmF2)}

In Fig. 3 is presented the monthly mean diurnal variation of $N m$ F2 simultaneously derived over the three different stations Trivandrum (Blue curve), Waltair (Green curve) and Delhi (Red curve) in each of the frames. It is observed from this figure that the diurnal variation of the peak electron density ( $N m$ F2) over Trivandrum shows a sharp day minimum around 06:00 LT with broad day maximum extending up to pre-midnight hours. There is a significant maintenance of night-time electron density during equinoctial and winter months which is also seen in TEC variation. Noon-time biteouts during equinoctial and summer months have been observed which are not significant in TEC. It is also seen from this figure that the diurnal behaviour of $N m \mathrm{~F} 2$ over Waltair shows a sharp day minimum around 06:00 LT with higher day-time values of $N m \mathrm{~F} 2$ compared to those at the equatorial station, Trivandrum. The night-time maintenance of electron density during equinoctial and winter months is observed 

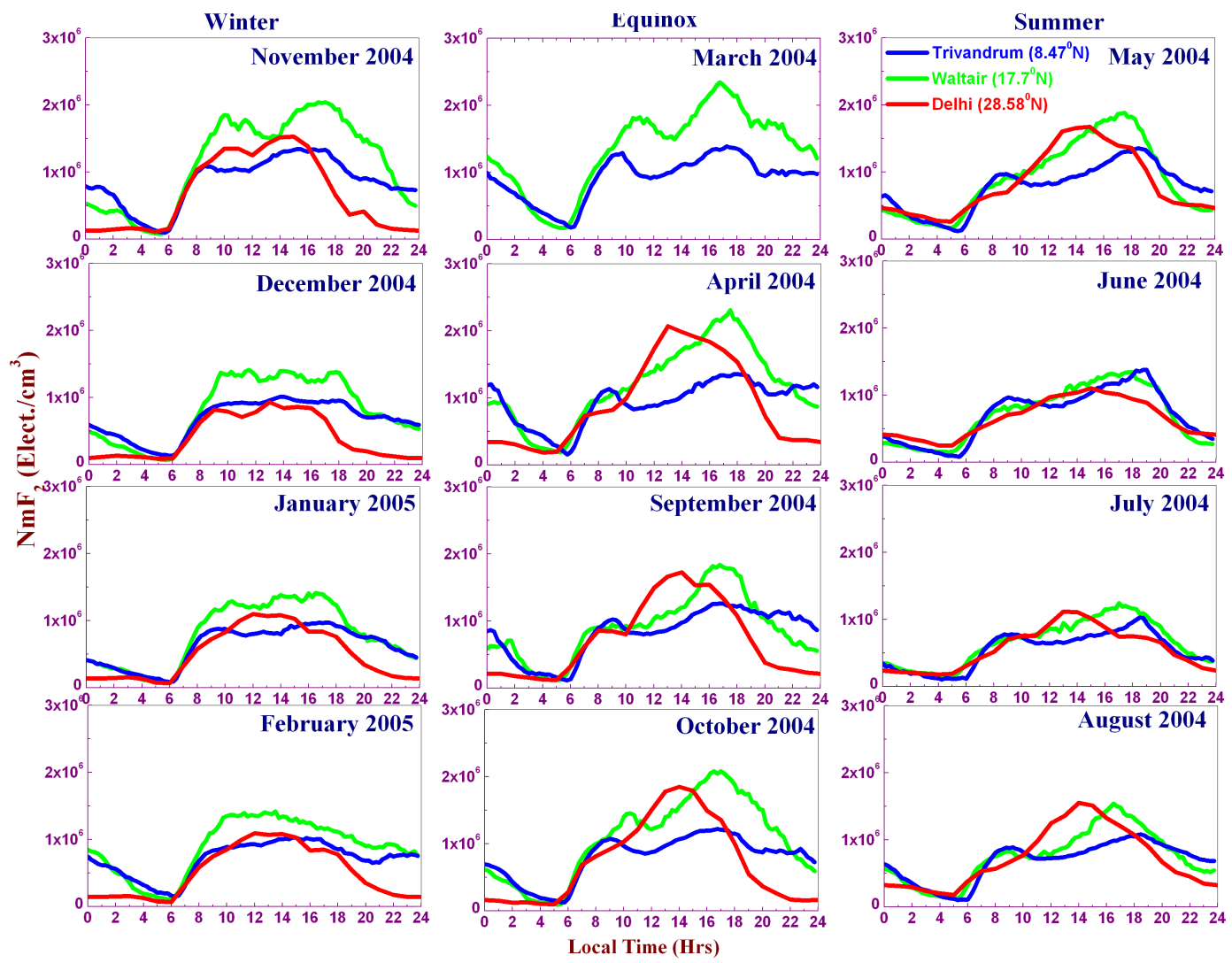

Fig. 3. Comparison of monthly mean diurnal variation of $N m \mathrm{~F} 2$ over three different stations Trivandrum $\left(8.47^{\circ} \mathrm{N}, 76.91^{\circ} \mathrm{E}\right)$, Waltair $\left(17.7^{\circ} \mathrm{N}, 83.3^{\circ} \mathrm{E}\right)$ and Delhi $\left(28.58^{\circ} \mathrm{N}, 77.21^{\circ} \mathrm{E}\right)$ during three different seasons.

similar to that at Trivandrum. In general, the $N m \mathrm{~F} 2$ values at Delhi are much lower than those at Trivandrum and Waltair. The sharp day minimum observed at Trivandrum and Waltair is absent over Delhi. The night-time electron density values at Delhi are mostly flat at the day minimum level during all the three seasons unlike those at Trivandrum and Waltair. The day maximum $N m \mathrm{~F} 2$ values at Delhi during equinoctial months are higher compared to those of winter and summer months.

In Fig. 4 are presented the mean diurnal variation of $N m \mathrm{~F} 2$ along with standard deviation represented by error bars for three typical months during the three different seasons over the three stations. There is a significant day-to-day variability over the three different stations with minimum variability over Trivandrum. Over Waltair, a station close to EIA region, a large day-to-day variability is observed particularly in the day maximum values of $\mathrm{Nm} \mathrm{F} 2$ during all the three seasons. The $N m \mathrm{~F} 2$ variation over Trivandrum and Waltair has shown more or less similar nature of variation with maximum values over Waltair during winter and equinoctial months. During summer months the night-time electron densities are similar at all the three different stations. A significant latitudinal variation in $N m \mathrm{~F} 2$ is also observed with higher values over Waltair. One interesting feature noticeable in the diurnal variation of $N m \mathrm{~F} 2$ at Trivandrum and Waltair is the presence of noon-time bite-out during the three different seasons. This may be due to the combined effect of the transport of plasma from the equator to EIA crest regions and the equatorward neutral winds (Balan and Bailey, 1995).

The average diurnal variation of the total electron content and the maximum electron density of the ionosphere for the three different seasons, winter, equinox and summer from the three different locations namely Trivandrum, Waltair and Delhi are simultaneously presented in Fig. 5. The bluecolored line represents the diurnal variation of TEC whereas the red-colored line represents $N m \mathrm{~F} 2$. It is observed from this figure that the maximum electron density $(\mathrm{NmF} 2)$ at all the three different stations show much lower values during most of the day-time hours compared to those of TEC. The trends of diurnal variation of TEC and $N m \mathrm{~F} 2$ are similar at Delhi with lower values compared to those at the other two stations. The behaviour of TEC and $N m \mathrm{~F} 2$ in the present study is in good agreement with the earlier studies using ATS-6 phase II measurements in the Indian equatorial region (Rastogi et al., 1979; Sethia et al., 1980). 

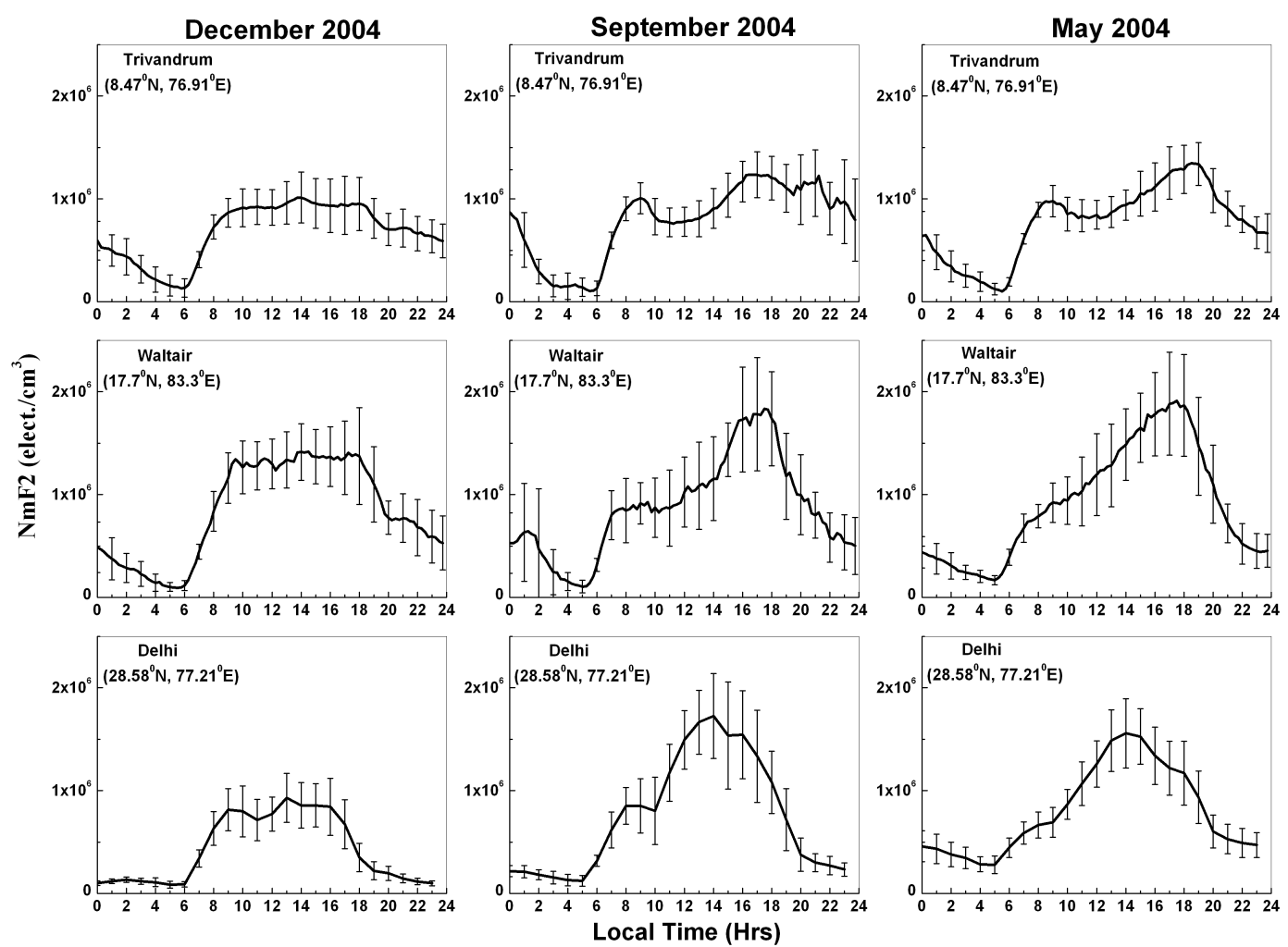

Fig. 4. Mean diurnal variation of $N m \mathrm{~F} 2$ along with standard deviation as error bars during three typical months (December, September and May 2004) representing three different seasons (winter, equinox and summer) for the three different stations namely Trivandrum, Waltair and Delhi.

\subsection{Variation of equivalent slab-thickness $(\tau)$}

The equivalent slab-thickness parameter " $\tau$ ", is a first order measure of the shape of the electron density profile of the ionosphere. Study of this parameter at the equatorial and low latitude stations provides information on the vertical ionization distribution in these regions. In Fig. 6 is presented the average diurnal variation of the equivalent slab-thickness $(\tau)$ at the three different stations, Trivandrum, Waltair and Delhi for different months. The seasonal mean for three different stations is plotted in each panel for each season in the bottom row. It may be readily seen from this figure that the equivalent slab-thickness shows a strong pre-sunrise peak around 05:00 LT at all the three different stations during all the seasons except during the summer months over Delhi. The existence of a pre dawn peak in equivalent slab-thickness has been reported earlier by Rastogi et al. (1979), Sethia et al. (1980), Bhuyan et al. (1986), Prasad et al. (1987), Davies and Liu (1991), Jayachandran et al. (2004) and Chuo (2007). The morning peak in slab-thickness was attributed to the rapid ionization of the topside ionosphere which increases the TEC while the peak electron density $(N m \mathrm{~F} 2)$ was lagging behind. Titheridge (1973) suggested that the presunrise peak in $\tau$ is due to the downward movement of the ionosphere. Large values of equivalent slab-thickness dur- ing predawn hours may also be attributed due to the fact that a significant portion of electrons in TEC are associated with $\mathrm{H}^{+}$ions which have large scale heights (Sethia et al., 1980). Soon after the occurrence of the morning peak, the slab-thickness decreases to a small value indicating a rapid production of ionization around the peak of F2-layer. The morning slab-thickness values over Waltair and Delhi are higher during winter months compared to those of equinoctial and summer months. Similar nature of variation was also reported earlier over Waltair, during a high solar activity period by Prasad et al. (1987). The results obtained over Delhi are consistent with those obtained by Stankov and Warnant (2009) and Chuo et al. (2010), in which a predawn enhancement in the slab-thickness and gradual disappearance from winter to summer at mid latitudes have been observed. The atmospheric neutral winds and enhanced eastward electric fields have significant and dominant influence on the peaks during these two periods (Chuo et al., 2010).

In general it is seen from Fig. 6 the equivalent slabthickness shows a variation of $\tau$ between 200 to $800 \mathrm{~km}$ during sunrise hours. Over the equatorial station, Trivandrum and the low latitude station, Waltair, a secondary maximum around noon-time hours has been observed in all the three different seasons. The day-time slab-thickness over Trivandrum and Waltair vary between 200 and $400 \mathrm{~km}$ at all 


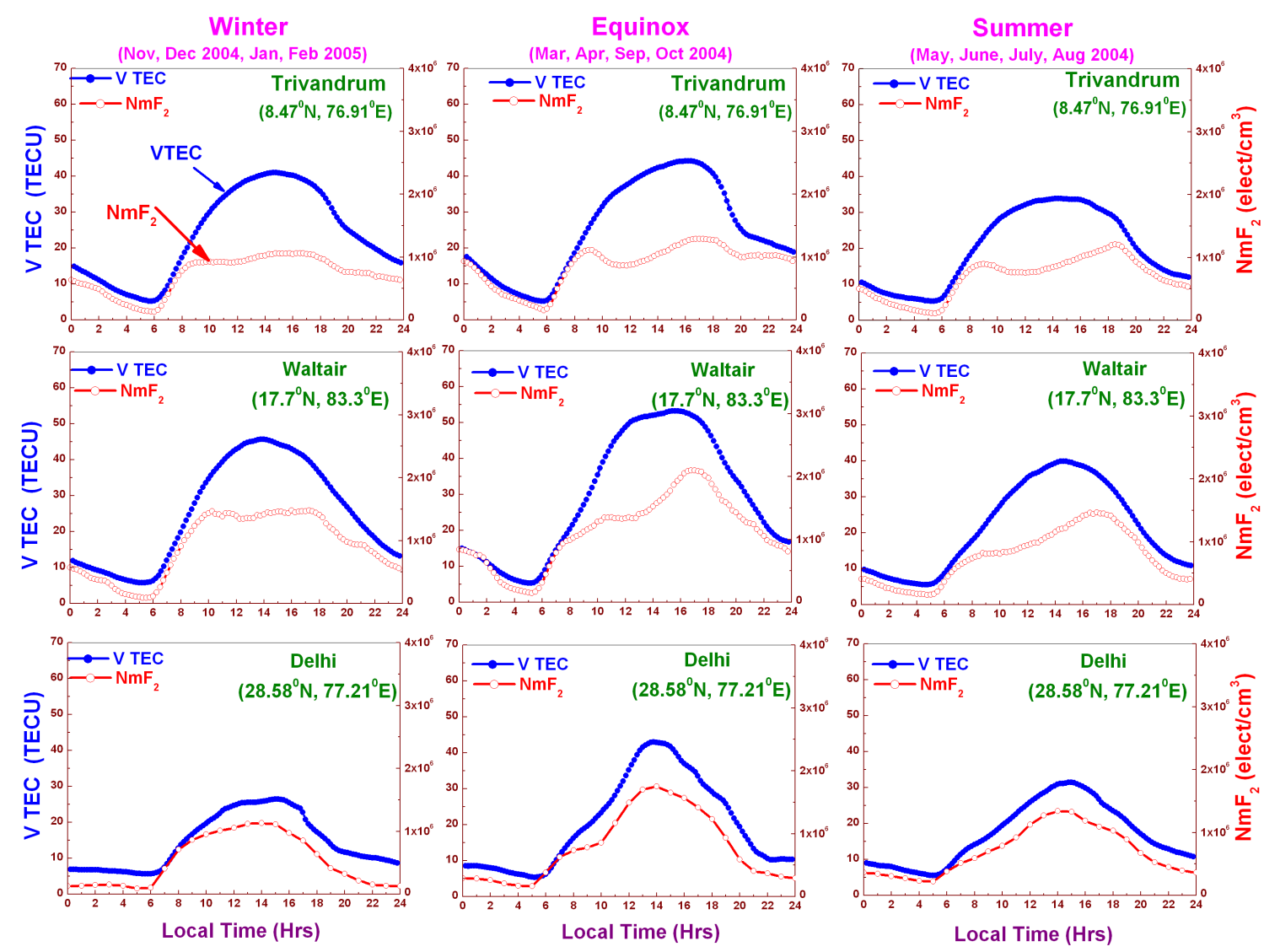

Fig. 5. The average diurnal variation of TEC and $N m \mathrm{~F} 2$ at three different stations Trivandrum $\left(8.47^{\circ} \mathrm{N}, 76.91^{\circ} \mathrm{E}\right), \mathrm{Waltair}\left(17.7^{\circ} \mathrm{N}, 83.3^{\circ} \mathrm{E}\right)$ and Delhi $\left(28.58^{\circ} \mathrm{N}, 77.21^{\circ} \mathrm{E}\right)$ during three different seasons.

the three stations whereas over the low-mid latitude station, Delhi, the day-time equivalent slab-thickness is mostly constant in all the three seasons varying around $250 \mathrm{~km}$. The secondary peak in the equivalent slab-thickness during daytime in the equatorial region is reported earlier by Rastogi et al. (1979). The occurrence of the secondary peak in the equivalent slab-thickness over an equatorial station, Trivandrum and low latitude station, Waltair is the clear reflection of the noon-time bite-outs that are observed in the diurnal variation of $N m \mathrm{~F} 2$ at these two stations.

Over the low-mid latitude station, Delhi, during winter months the night-time (19:00 to 06:00 LT) slab-thickness values are significantly high varying from about 400 to $800 \mathrm{~km}$. The night-time enhancement in the slab-thickness during winter months has been reported earlier by Essex (1978), Prasad et al. (1987), Jayachandran et al. (2004) for both low and high solar activity periods. The decrease in the transition height of $\mathrm{O}^{+} / \mathrm{H}^{+}$ratio during winter nights results in the decrease in the mean ion mass on the topside ionosphere which may cause an increase in the scale height that results in an increase in the slab-thickness. During winter months the slab-thickness decreases from 00:00 to 03:00 $\mathrm{h}$ and a sharp peak around 06:00 h has been observed over Delhi. Similar nature of variation in the equivalent slab-thickness has been observed during winter months over Ahmedabad (Bhar et al., 1976).

At the equatorial and low latitude regions $\boldsymbol{E} \times \boldsymbol{B}$ drifts originating at the equator play a significant role in the vertical distribution of ionization and the electron density gradients. The variation in the skewness of the electron density distribution at the equator and beyond can be explained by studying the latitudinal variation of slab-thickness, which is presented in Fig. 6. The slab-thickness shows a clear latitudinal variation with higher day-time values at Trivandrum and lower values at a low-mid latitude station Delhi compared to those at Trivandrum and Waltair. From this result, it can be inferred that the day-time vertical electron density distribution becomes more skewed as we go away from the equator to the low and low-mid latitude regions.

\subsection{Variation of neutral temperature $\left(T_{n}\right)$}

Titheridge (1973) holds that the equivalent slab-thickness gives primarily a measure of the temperature of the neutral gas and has given a relation $\left(T_{\mathrm{n}}=(\tau-15) / 0.25\right)$ to compute neutral temperatures $\left(T_{\mathrm{n}}\right)$ using the slab-thickness 

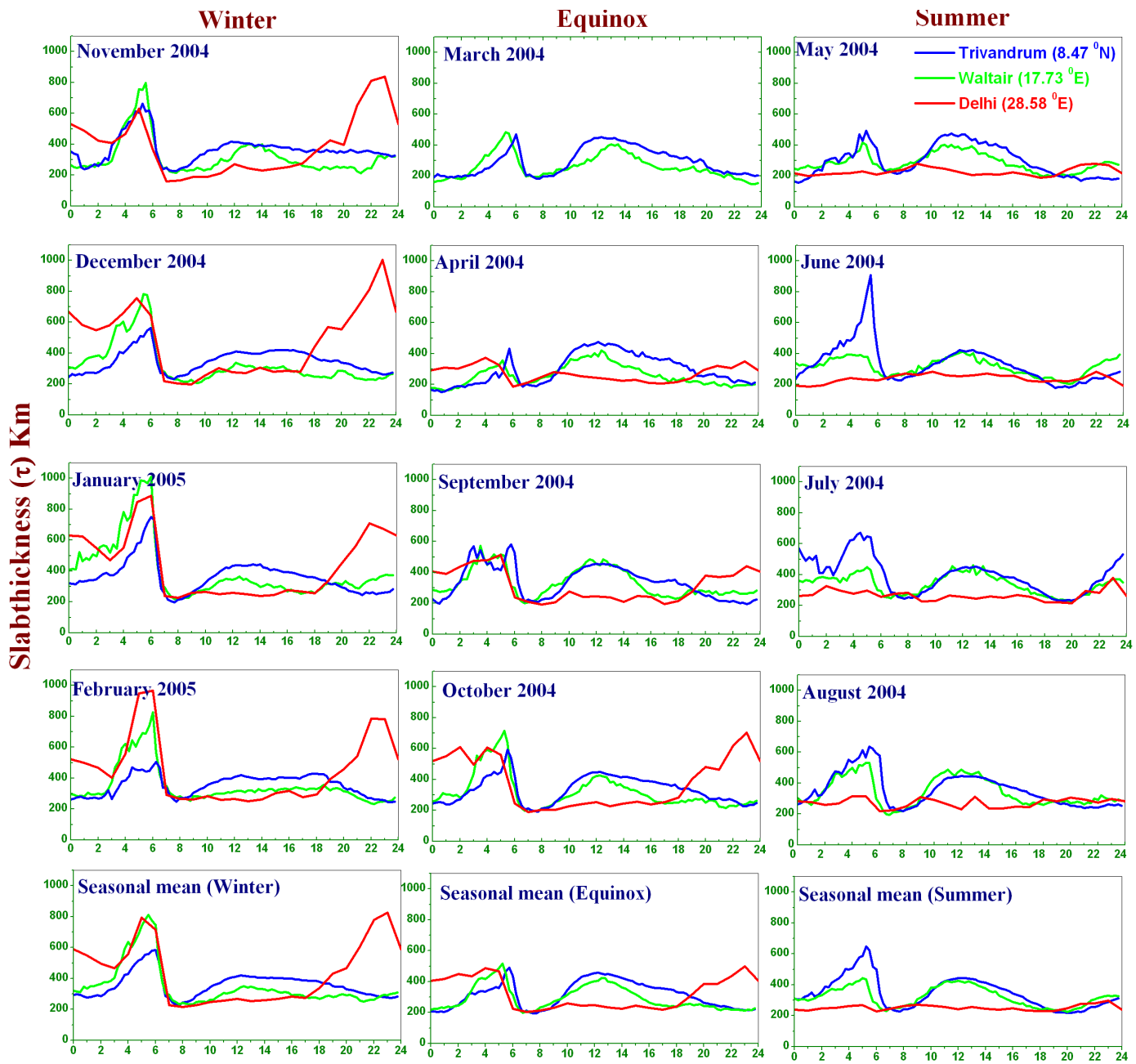

Local Time (Hrs)

Fig. 6. Comparison of monthly mean diurnal variation of equivalent slab-thickness $(\tau)$ over three different stations Trivandrum $\left(8.47^{\circ} \mathrm{N}\right.$, $\left.76.91^{\circ} \mathrm{E}\right)$, Waltair $\left(17.7^{\circ} \mathrm{N}, 83.3^{\circ} \mathrm{E}\right)$ and Delhi $\left(28.58^{\circ} \mathrm{N}, 77.21^{\circ} \mathrm{E}\right)$ for different months. The bottom row represents seasonal mean for three different stations in each panel for three different seasons.

$(\tau)$ values for mid latitudes which is used in the present study for the low-mid latitude station, Delhi. Modified versions of Titheridge relation have been used to compute neutral temperatures for the equatorial station Trivandrum $\left(T_{\mathrm{n}}=(\tau+275) / 0.677\right)$ and for a low latitude station Waltair $\left(T_{\mathrm{n}}=(\tau+243) / 0.621\right)$. In Fig. 7 is shown the monthly mean diurnal variation of the Neutral Temperatures $\left(T_{\mathrm{n}}\right)$ derived using equivalent slab-thickness $(\tau)$ (blue curves) along with the MSIS-90 model derived neutral temperatures (magenta curves) for the three different stations Trivandrum, Waltair and Delhi for the three different seasons.

It is observed from this figure that the diurnal variation of the neutral temperatures at the three different stations during the three different seasons show similar nature of variations similar to those of the equivalent slab-thickness. At the equatorial and low latitude stations the neutral temperature shows a peak around 05:00 LT with the temperature values vary- ing from 1000 to $1500^{\circ} \mathrm{K}$. During the rest of the day and night-time hours the neutral temperature varies from a minimum of 700 to a maximum of $1000^{\circ} \mathrm{K}$. However, at Delhi a double peaking is observed during winter and equinox months reaching peak values of $3500^{\circ} \mathrm{K}$ around 05:00 LT and 23:00 LT. Whereas at Delhi, during summer months, the neutral temperature remains constant around $1000^{\circ} \mathrm{K}$ during all the $24 \mathrm{~h}$ of the day similar to those of the day-time values in winter and equinoctial months. Except for the morning peak, the neutral temperatures derived from slab-thickness compare well with the MSIS-90 model derived temperatures. These temperatures are compared with SROSS-C2 measurements at Bhopal $\left(23^{\circ} \mathrm{N}\right.$ Geog. lat.) (Niranjan et al., 2003), which also show a double peaking around 05:00 LT and 17:00 LT during the June solstice with a variation between $2000^{\circ} \mathrm{K}$ to $3000^{\circ} \mathrm{K}$. However, similar double peaking is also observed in the present study during equinoctial and 

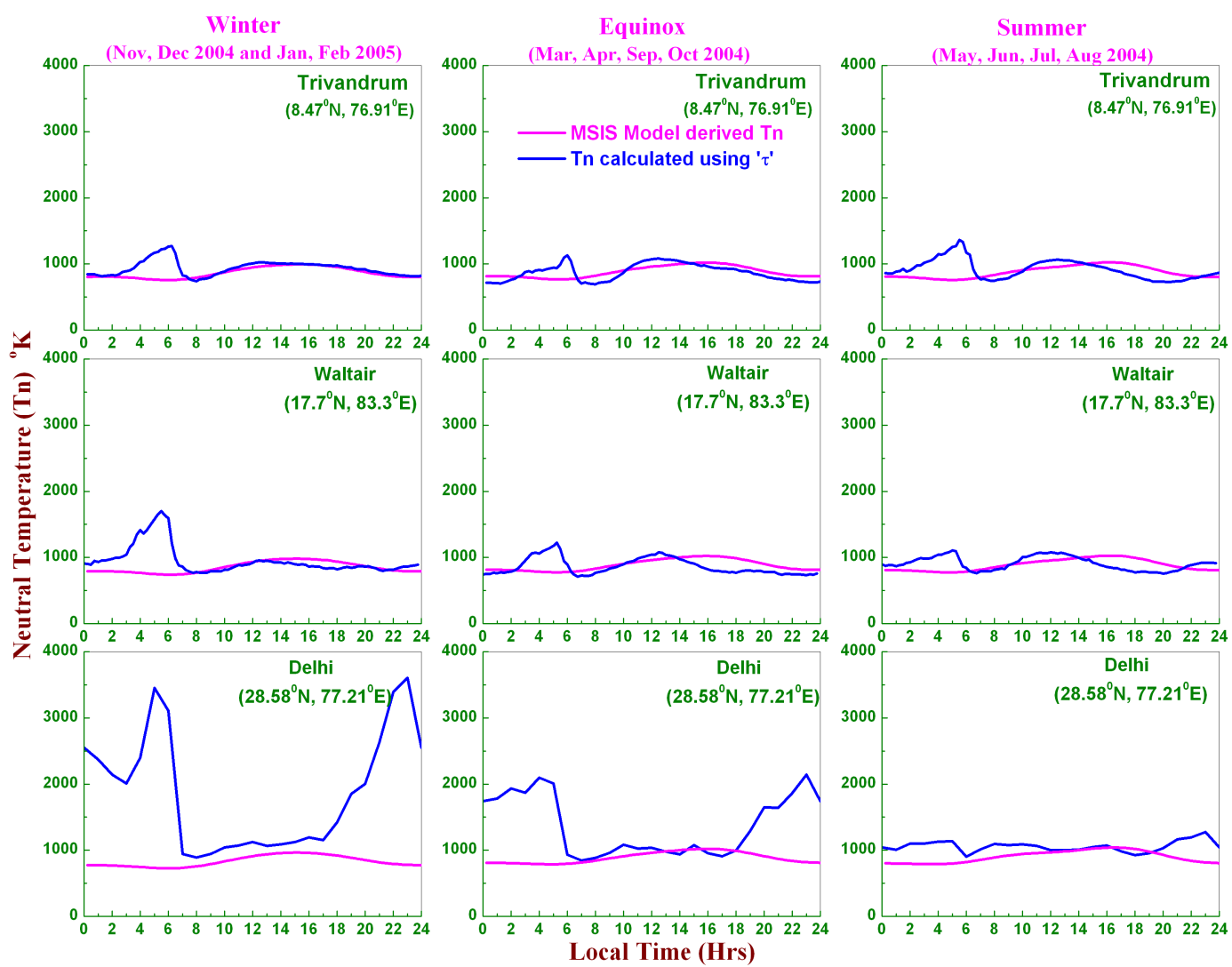

Fig. 7. Monthly mean diurnal variation of Neutral Temperatures $\left(T_{\mathrm{n}}\right)$ derived using equivalent slab-thickness $(\tau)$ (blue curves) and their comparison with MSIS-90 modeled temperatures (magenta curves) over three different stations Trivandrum $\left(8.47^{\circ} \mathrm{N}, 76.91^{\circ} \mathrm{E}\right)$, Waltair $\left(17.7^{\circ} \mathrm{N}, 83.3^{\circ} \mathrm{E}\right)$ and Delhi $\left(28.58^{\circ} \mathrm{N}, 77.21^{\circ} \mathrm{E}\right)$ during three different seasons.

winter months over Delhi ( $28^{\circ} \mathrm{N}$ Geog. lat.) with temperatures varying between $2000^{\circ} \mathrm{K}$ to $3400^{\circ} \mathrm{K}$. The difference in the seasonal behaviour of the temperatures may be due to the latitudinal difference between Bhopal and Delhi which are located at the EIA crest region and at the outer edge of the EIA respectively, where there is a steep decrease in the electron density at Delhi effecting the ratios of TEC/NmF2 differently at the two different locations. The morning peak in the neutral temperatures may be attributed to the influx of photoelectrons from the conjugate hemisphere, expanding the topside ionosphere and producing the observed increase in electron temperature (McClure, 1969; Wand, 1970). In general, the neutral temperatures computed from the equivalent slab-thickness using Titheridge method are comparable with those of the MSIS-90 model derived temperatures particularly during all day-time hours.

\section{Summary}

A study on the diurnal, day-to-day, seasonal and latitudinal variation of TEC, $N m \mathrm{~F} 2$, equivalent slab-thickness $(\tau)$ and neutral temperatures $\left(T_{\mathrm{n}}\right)$ over three different Indian stations
Trivandrum (Equatorial station), Waltair (located at the inner edge of EIA) and Delhi (located at the outer edge of the EIA) during the low sunspot period of 2004-2005 has been carried out. The diurnal variation of TEC shows a sharp day minimum value around 05:00 LT during all the three different seasons over Trivandrum and Waltair. The day-to-day variability in the day maximum values of TEC is higher over Waltair and Delhi compared to that at Trivandrum. The day maximum values of TEC are higher during equinoctial months at the three different stations. There is a significant latitudinal variation in the day maximum values of TEC with minimum values at Delhi and maximum values at Waltair. The night-time ionization during winter and equinoctial months is higher over Waltair and Trivandrum compared to that at Delhi.

The maximum electron density of the F2-layer $(\mathrm{NmF} 2)$ at all the three different stations more or less show similar nature of variation with much lower values during most of the day-time compared to those of TEC. One interesting feature noticeable in the diurnal variation of $N m \mathrm{~F} 2$ at Trivandrum and Waltair is the presence of noon-time bite-out during the three different seasons, which is absent at Delhi. The slab-thickness shows similar features at Trivandrum and 
Waltair during the three different seasons whereas at Delhi the features are different. At Trivandrum and Waltair, a significant and large early morning increase in slab-thickness around 05:00 LT (except during summer at Waltair) is observed. During day-time, the slab-thickness has shown lower values at a low-mid latitude station, Delhi compared to those at Trivandrum and Waltair. During the day-time a secondary peak in the slab-thickness is observed over the equatorial station, Trivandrum and the low latitude station, Waltair. A significant latitudinal variation in the equivalent slab-thickness with higher day-time values over Trivandrum has been observed. From the latitudinal variation of slab-thickness, it can be inferred that the day-time vertical electron density distribution becomes more skewed as we go away from the equator to the low and low-mid latitude regions. The neutral temperatures computed from the slab-thickness $(\tau)$ using Titheridge (1973) method show a sharp increase around 05:00 LT over Trivandrum and Waltair and a double peaking around 05:00 LT and 23:00 LT during winter and equinoctial months over Delhi. The neutral temperature values derived from the two different methods (using slab-thickness and MSIS model) has shown a reasonably good agreement.

Acknowledgements. The authors wish to express their sincere thanks to late Sudha Ravindran, SPL, VSSC, Trivandrum and R. S. Dabas NPL, New Delhi for providing the ionosonde data. One of the authors (K.V) wish to express his sincere thanks to SPL, VSSC, Trivandrum for providing JRF under ISRO-CRABEX project.

Topical Editor K. Kauristie thanks two anonymous referees for their help in evaluating this paper.

\section{References}

Aravindan, P. and Iyer, K. N.: Day to day variability in ionospheric electron content at low latitudes, Planet. Space Sci., 38, 743-750, 1990.

Bagiya, Mala S., Joshi, H. P., Iyer, K. N., Aggarwal, M., Ravindran, S., and Pathan, B. M.: TEC variations during low solar activity period (2005-2007) near the Equatorial Ionospheric Anomaly Crest region in India, Ann. Geophys., 27, 1047-1057, doi:10.5194/angeo-27-1047-2009, 2009.

Balan, N. and Bailey, G. J.: Equatorial plasma fountain and its effects: possibility of an additional layer, J. Geophys. Res., 100, 21421-21432, 1995.

Bhar, J. N., Basu, S., Das Gupta, A., Guhathakurta, B. I., and Bhattacharyya, G. N.: Investigations on ionospheric electron content and electron density irregularities at low latitudes with geostationary satellites, Institute of Radio Physics and electronics, final scientific report, 1976.

Bhonsle, R. V., Da Rosa, A. V., and Garriott, O. K.: Measurement of Total Electron Content and the Equivalent Slab Thickness of the Mid latitude Ionosphere, Radio Science, 69D, 929-939, 1965.

Bhuyan, P. K. and Rashmi Rekha Borah: TEC derived from GPS network in India and comparison with the IRI, Adv. Space Res., 39, 830-840, 2007.
Bhuyan, P. K., Lakha Singh, and Tyagi, T. R.: Equivalent slab thickness of the ionosphere over $26^{\circ} \mathrm{N}$ through the ascending half of a solar cycle, Ann. Geophys., 4, 131-136, 1986.

Chuo, Y. J.: The variation of ionospheric slab thickness over equatorial ionization area crest Region, J. Atmos. Terrestrial Phys., 69, 947-954, 2007.

Chuo, Y. J., Lee, C. C., and Chen, W. S.: Comparison of ionospheric equivalent slab thickness with bottomside digisonde profile over Wuhan, J. Atmos. Solar Terr. Phy., 72, 528-533, 2010.

Dabas, R. S., Bhuyan, P. K., Tyagi, T. R., Bhardwaj, R. K., and Lal, J. B.: Day-to-day changes in ionospheric electron content at low latitudes, Radio Sci., 19, 749-756, 1984.

Davies, K. and Liu, X. M.: Ionospheric slab thickness in middle and low-latitudes, Radio Sci., 26, p. 997, 1991.

Essex, E. A.: Ionospheric total electron content at southern midlatitudes during 1971-74, J. Atmos. Terr. Phys., 40, 1019-1024, 1978.

Gulyaeva, T. L., Jayachandran, B., and Krishnankutty, T. N.: Latitudinal variation of ionospheric slabthickness, Adv. Space Res., 33, 862-865, 2004.

Hibberd, F. H. and Ross, W. J.: Total Electron Content of the Ionosphere in middle latitudes, J. Geophys. Res., 71, 2243-2253, 1966.

Jayachandran, B., Krishnankutty, T. N., and Gulyaeva, T. L.: Climatology of ionospheric slab thickness, Ann. Geophys., 22, 25-33, doi:10.5194/angeo-22-25-2004, 2004.

Mahajan, K. K., Rao, P. B., and Prasad, S. S.: Incoherent backscatter study of electron content and equivalent slab thickness, J. Geophys. Res. (USA), 73, 2477-2486, 1968.

McClure, J. P.: Diurnal variation of neutral and charged particle temperatures in the equatorial F-Region, J. Geophys. Res., 74, 279-291, 1969.

Niranjan, K., Sridhar, H. S., Rama Rao, P. V. S., Garg, S. C., and Subrahmanyam, P.: Evening enhancements in F-region electron temperature at subtropical latitudes during june solstice in the Indian SROSS C2 RPA data, J. Atmos. Solar Terr. Phys., 65, 813-819, 2003.

Pande, V. K., Mahajan, K. K., Jain, V. C., and Kohli, R.: Study of TEC \& equivalent slab thickness \& their relationship with ion drifts and ionospheric temperatures, Indian J. Radio Space Phys., 13, 116-118, 1984.

Prasad, D. S. V. V. D., Niranjan, K., and Rama Rao, P. V. S.: TEC and equivalent slab-thickness at low \& mid latitudes-A comparative study, Indian J. Radio Space Phys., 16, 295-297, 1987.

Rama Rao, P. V. S., Sri Rama Rao, M., and Satyam, M.: Diurnal and seasonal trends in TEC values observed at Waltair, Indian J. Radio Space Phys., 6, 233-235, 1977.

Rastogi, R. G. and Alex, S.: Day to day variability of ionospheric electron content at low latitudes, J. Atmos. Terr. Phys., 49, 11331137, 1987.

Rastogi, R. G., Iyer, K. N., and Bhattacharya, J. C.: Total electron content of the ionosphere over the magnetic equator, Current Science, 44, 531-533, 1975.

Rastogi, R. G., Iyer, K. N., and Sharma, R. P.: Ionospheric total electron content and slab-thickness at low latitudes in Indian zone, Proc. Indian Acad. Sci., 85A, 415-428, 1977.

Rastogi, R. G., Sethia, G., Chandra, H., Deshpande, M. R., Davies, K., and Murthy, B. S.: Total electron content and F-region electron density distribution near the magnetic equator in India, J. 
Atmos. Terr. Phys., 41, 561-564, 1979.

Sethia, G., Chandra, H., Deshpande, M. R., and Rastogi, R. G.: Radio beacon studies of equatorial electron content, Low latitude aeronomical processes, Advances in Space Exploration, vol. 8, edited by: Mitra, A. P., 1980.

Stankov, S. M. and Warnant, R.: Ionospheric slabthickness - analysis, modeling and Monitoring, Adv. Space Res., 44, 1295-1303, 2009.
Titheridge, J. E.: The slab thickness of the mid-latitude ionosphere, Planet. Space Sci., 21, 1775-1793, 1973.

Wand, R. H.: Electron/ion temperature ratio from radar Thomson scatter observations, J. Geophys. Res., 75, 829-838, 1970.

Yeh, K. C. and Flaherty, B. J.: Ionospheric Electron Content at temperate latitudes during the declining phase of the sunspot cycle, J. Geophys. Res., 71, 4557-4570, 1966. 